\title{
Hybrid ZVS Converter with a Wide ZVS Range and a Low Circulating Current
}

\author{
Bor-Ren $\operatorname{Lin}^{\dagger}$ and Jia-Sheng Chen ${ }^{*}$ \\ ${ }^{\dagger *}$ Department of Electrical Engineering, National Yunlin University of Science and Technology, Yunlin, Taiwan
}

\begin{abstract}
This paper presents a new hybrid soft switching dc-dc converter with a low circulating current and high circuit efficiency. The proposed hybrid converter includes two sub-converters sharing two power switches. One is a three-level PWM converter and the other is a $L L C$ converter. The $L L C$ converter and the three-level converter share the lagging-leg switches and extend the zero-voltage switching (ZVS) range of the lagging-leg switches from nearly zero to full load since the $L L C$ converter can be operated at $f_{s w}$ (switching frequency) $\approx f_{r}$ (series resonant frequency). A passive snubber is used on the secondary side of the three-level converter to decrease the circulating current on the primary side, especially at high input voltage and full load conditions. Thus, the conduction losses due to the circulating current are reduced. The output sides of the two converters are connected in series. Energy can be transferred from the input voltage to the output load within the whole switching period. Finally, the effectiveness of the proposed converter is verified by experiments with a $1.44 \mathrm{~kW}$ prototype circuit.
\end{abstract}

Key words: Hybrid three-level PWM converter, LLC converter, Phase-shift PWM, ZVS

\section{INTRODUCTION}

Full-bridge converters with a high power density and high efficiency have been proposed and used in many industry products such as server power units [1], telecommunication power units [2], and electric vehicle (EV) and plug-in hybrid electric vehicle (PHEV) battery chargers [3], [4]. Single-phase power factor correction (PFC) is normally adopted in the front stage to eliminate the current harmonics, increase the input power factor and keep the dc bus voltage at a constant voltage against line voltage and load current variations. For medium/high power ratings, power converters with a three-phase ac utility are adopted to reduce the current rating from the ac source. The power factors of these converters are normally required to improve the power quality of utility systems. Three-phase PFC with a unidirectional or bidirectional power flow and bridge/bridgeless circuit topologies can be adopted in the front stage. However, the dc bus voltage of the three-phase PFC will be higher than $750 \mathrm{~V}$ or $800 \mathrm{~V}$. Thus, the power

Manuscript received Dec. 29, 2014; accepted Feb. 11, 2015 Recommended for publication by Associate Editor Yan Xing.

${ }^{\dagger}$ Corresponding Author: linbr@yuntech.edu.tw

Tel: +886-5-534-2601 ext. 4202, Fax: +886-5-531-2065, YunTech.

*Department of Electrical Engineering, National Yunlin University of Science and Technology, Taiwan switches in the dc-dc converters of the rear stage must have $900 \mathrm{~V}$ or $1200 \mathrm{~V}$ voltage stress. Three-level dc-dc converters [5]-[7] with low voltage stress of the active switches are widely used in industry applications due to their high switching frequency and small size demands. Phase-shift pulse-width modulation (PWM) is normally adopted to generate the gate voltages of three-level converters. The main drawback of phase-shift PWM is that the lagging-leg switches have a narrow range of ZVS operation due to the limited energy stored in the primary leakage inductance. To overcome this problem, a large leakage inductance [8] or an external resonant inductance [3] can be placed on the primary side to extend the ZVS range of the lagging-leg switches. However, this approach also increases the duty cycle loss and decreases the effective duty cycle on the secondary side. In [9], [10], auxiliary circuits are added on the primary side to increase the ZVS load range. The switching power losses of the switches are improved. However, the power losses of the additional auxiliary circuits will decrease the total circuit efficiency. Recently, an $L L C$ converter and a full-bridge converter sharing lagging-leg switches have been studied in [11], [12]. Thus, the ZVS range of the switches can be extended from zero to full load conditions. The other main problem of the phase-shift PWM scheme for full-bridge converters and three-level converters is its high circulating 
current during the freewheeling interval. To overcome this drawback, active or passive clamp circuits [4] and [13] can be added on the secondary side to limit voltage overshoots and oscillations across the output diodes when they are turned off, and to improve the circulating current losses on the primary side. However, an additional gate driver is needed to control the secondary active switch which will increase the circuit complexity and decrease the circuit reliability.

A hybrid three-level ZVS converter is studied in this paper to have the advantages of wide range of ZVS operation and low circulating current losses. The proposed hybrid converter combines a conventional three-level PWM converter and a half-bridge $L L C$ converter with fixed switching frequency sharing of the lagging-leg switches to reduce the switch counts. Since the switching frequency of the $L L C$ converter is greater than the series resonant frequency, the active switches at the lagging-leg can be turned on under ZVS from zero to full load conditions. The output voltages of the half-bridge LLC converter and the three-level PWM converter are connected in series. Thus, energy can be transferred from the input to the output load within the whole switching cycle. A passive snubber is adopted on the secondary side to provide a positive rectified voltage during the freewheeling interval to decrease the primary side current. Thus, the high circulating current in the conventional three-level PWM converter is rapidly reduced and the converter efficiency is improved. In the meantime, the rectified voltage on the secondary side during the freewheeling interval is positive instead of zero in the conventional three-level converter. The output inductance in the proposed hybrid converter can also be reduced. Finally, experiments with a $1.44 \mathrm{~kW}$ prototype circuit are provided to demonstrate the performance of the proposed converter.

\section{PROPOSED CONVERTER}

Fig. 1 shows a general three-phase ac-dc converter for industry power units. The front-stage is a three-phase power factor corrector to achieve a low total harmonic distortion of the three-phase line currents, a high power factor and a stable high dc bus voltage. The second stage is a high frequency link dc-dc converter based on a full-bridge converter with IGBT power switches or a three-level PWM converter with power MOSFETs to provide a stable low dc bus voltage and high load current. In order to reduce the converter size and weight, a three-level PWM converter with power MOSFETs and a high switching frequency is generally used to achieve this demand. Fig. 2 shows a circuit diagram of the proposed high frequency dc-dc converter to overcome the disadvantages of conventional three-level PWM converters. There are two sub-converters in the proposed dc-dc converter. One is a three-level PWM converter $\left(C_{d 1}, C_{d 2}, D_{1}, D_{2}, C_{f}\right.$, $S_{1}-S_{4}, T_{1}, L_{r 1}, D_{r 1}, D_{r 2}, C_{c}, D_{a}, D_{b}, L_{o}$ and $C_{o 1}$ ) and the other is an $L L C$ circuit $\left(C_{f}, S_{2}, S_{3}, L_{r 2}, C_{r}, T_{2}, D_{r 3}, D_{r 4}\right.$ and $\left.C_{o 2}\right) . S_{1}$ and

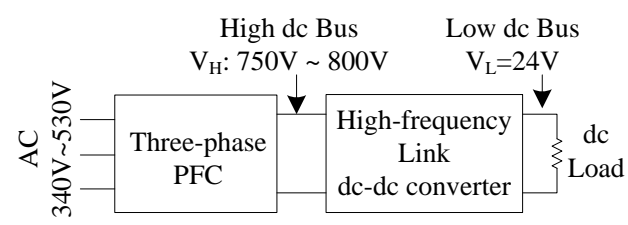

Fig. 1. Three-phase ac-dc converter with two-stage conversion.

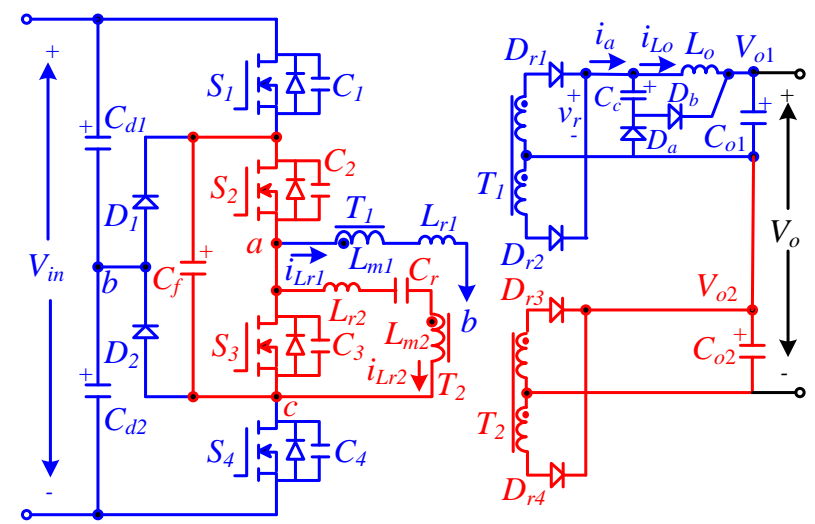

Fig. 2. Circuit diagram of the proposed hybrid ZVS converter.

$S_{4}$ are in the leading-leg, and $S_{2}$ and $S_{3}$ are in the lagging-leg. The $L L C$ circuit is operated at a fixed switching frequency so that the output voltage $V_{o 2}$ is un-regulated. However, the total output voltage $V_{o}$ is regulated by the three-level PWM circuit using the phase-shift PWM scheme. The energy stored in the output inductor $L_{o}$ is reflected to the primary side to help the leading-leg switches turn-on at ZVS from light load to full load conditions. The $L L C$ circuit, sharing the lagging-leg switches $S_{2}$ and $S_{3}$ of the three-level PWM circuit, is operated at a fixed switching frequency. The adopted switching frequency $f_{s w}$ is close to the series resonant frequency $f_{r}$ in the $L L C$ circuit. The lagging-leg switches $S_{2}$ and $S_{3}$ can be turned on at ZVS from nearly zero to full load conditions. Thus, power switches $S_{1}-S_{4}$ in the proposed circuit have a wide range of ZVS operation when compared to the ZVS range in the conventional three-level converter. In order to reduce the circulating current of the three-level converter, a passive snubber circuit including $C_{c}, D_{a}$ and $D_{b}$ is used on the secondary side to provide a dc voltage during the freewheeling interval. During the freewheeling interval, the rectified voltage $v_{r}=v_{C c}$. The reflected voltage $n_{1} v_{r}$ is applied to $L_{r 1}$ on the primary side to reduce the circulating current to zero, and the output inductor voltage $v_{L o}=v_{C c}-v_{o 1}$ instead of $-v_{o 1}$. Thus, the high circulating current losses in the conventional three-level converter are improved in the proposed converter. Since the output voltages of the three-level circuit and the $L L C$ circuit are connected in series, the input energy of the $L L C$ circuit can be delivered to the output load in the whole switching cycle.

\section{OPERATION PRINCIPLES}




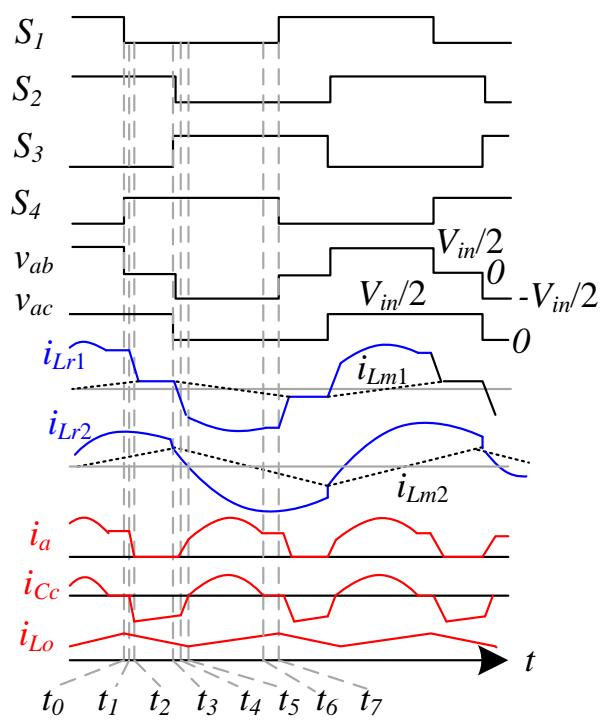

Fig. 3. Key waveforms of the proposed converter during one half of switching cycle.

In the proposed converter, the turn-on time of each power switch is equal to half of a switching period. The PWM signal of $S_{2}\left(S_{3}\right)$ is phase-shifted with respect to the PWM signal of $S_{1}\left(S_{4}\right) . S_{1}\left(S_{2}\right)$ and $S_{4}\left(S_{3}\right)$ operate complementarily with a short dead time to avoid short circuits. The operation principles of the proposed converter are based on the following assumptions. 1) MOSFETs $S_{1}-S_{4}$ and rectifier diodes $D_{r 1}-D_{r 4}, D_{1}-D_{2}$ and $D_{a}-D_{b}$ are ideal, 2) capacitor voltages $v_{C d 1}, v_{C d 2}, v_{C f}, V_{o 1}$ and $V_{o 2}$ are constant, the turns ratios of $T_{1}$ and $T_{2}$ are $n_{1}=n_{p 1} / n_{s 1}$ and $n_{2}=n_{p 2} / n_{s 2}$, respectively, and 3) $C_{1}=C_{2}=C_{3}=C_{4}=C_{o s s}$ and $V_{C d 1}=V_{C d 2}=V_{C f}=V_{\text {in }} / 2$. Fig. 3 illustrates the key PWM waveforms of the proposed converter in a switching cycle. According to the switching states of $S_{1}-S_{4}, D_{r 1}-D_{r 4}, D_{1}-D_{2}$ and $D_{a}-D_{b}$, the converter has seven operation modes in each half of a switching period. Fig. 4 gives the equivalent circuits for the seven operation modes.

Mode 1 [ $t_{0}-t_{1}$ ]: Prior to $t_{0}$, the power semiconductors $S_{1}, S_{2}$, $D_{r 1}$ and $D_{r 3}$ are conducting. Both of the inductor currents $i_{L r 1}$ and $i_{L r 2}$ are positive. $S_{1}$ is turned off at $t_{0} . C_{1}$ and $C_{4}$ are charged and discharged, respectively, by $i_{L r 1}$. The energy stored in the output inductor $L_{o}$ and the primary inductor $L_{r 1}$ is used to discharge $C_{4}$ to zero voltage. The ZVS condition of $S_{4}$ is illustrated in (1).

$$
\left(L_{r 1}+n_{1}^{2} L_{o}\right) i_{L r 1}^{2}\left(t_{0}\right) \geq \frac{C_{o s s} V_{i n}^{2}}{2}
$$

This mode ends at $t_{1}$ when $v_{C 1}=V_{\text {in }} / 2$ and $v_{C 4}=0$. The time interval of mode 1 is given in (2).

$$
\Delta t_{01}=t_{1}-t_{0}=\frac{C_{\text {oss }} V_{\text {in }}}{i_{L r 1}\left(t_{0}\right)} \approx \frac{C_{\text {oss }} V_{\text {in }}}{i_{L o, \max } / n_{1}}
$$

The dead time between $S_{1}$ and $S_{4}$ must be greater than $\Delta t_{01}$ to achieve the ZVS operation of $S_{4}$.

Mode $2\left[\boldsymbol{t}_{\boldsymbol{1}}-\boldsymbol{t}_{2}\right]$ : Mode 2 starts at $t_{1}$ when $v_{\mathrm{C} 1}=V_{\text {in }} / 2, v_{\mathrm{C} 4}=0$, and $D_{1}$ and $D_{a}$ are on. Since $i_{L r 1}$ is positive, the output diode of $S_{4}$ is conducting. At this moment, $S_{4}$ can be turned on under ZVS. In this mode, the primary side voltages $v_{a b}=0$ and $v_{a c}=v_{C f}=V_{i n} / 2$ in the steady state. Since $D_{a}$ is on, the rectified voltage $v_{r}=v_{C c}$ and $v_{L o}=v_{C c}-V_{o 1}<0$. The inductor current $i_{L o}$ decreases with a slope of $\left(v_{C c}-V_{o 1}\right) / L_{o}$. The reflected secondary windings voltage $-n_{1} v_{C c}$ is applied to $L_{r 1}$ so that the primary side current $i_{L r 1}$ rapidly decreases to zero with a slope of $-n_{1} v_{C c} / L_{r 1}$. The time interval in mode 2 is obtained in (3).

$$
\Delta t_{12}=t_{2}-t_{1}=\frac{L_{r 1} i_{L o}\left(t_{2}\right) / n_{1}}{n_{1} v_{C c}} \approx \frac{L_{r 1} I_{o}}{n_{1}^{2} v_{C c}}
$$

In the conventional three-level converter, the primary current $i_{L r 1}$ in this mode is kept at the same value of $i_{L r 1}\left(t_{1}\right)$ because $v_{L r 1}=0$. Thus, the conventional three-level converter has large circulating current losses during the freewheeling interval. The energy stored in the clamped capacitor $C_{c}$ is transferred to the output load through $L_{o}$ and $D_{a}$. The secondary winding current $i_{a}$ decreases in this mode. The $L L C$ converter is still in the resonant mode to transfer energy from the input to the output load.

Mode 3 [ $\left.\boldsymbol{t}_{2}-\boldsymbol{t}_{3}\right]$ : Mode 3 starts at $t_{2}$ when the secondary winding current $i_{a}$ decreases to zero, and the capacitor current $i_{C c}=-i_{L o}$. The primary side current $i_{L r 1}$ is approximately zero and the primary and secondary sides of $T_{1}$ are disconnected. There is no circulating current loss in this mode. The output inductor voltage $v_{L o}=v_{C c}-V_{o 1}<0$ and $i_{L o}$ decreases. The $L L C$ circuit continuously transfers energy from $C_{f}$ to the output load.

Mode 4 [ $\boldsymbol{t}_{3}-\boldsymbol{t}_{\mathbf{4}}$ ]: Mode 4 starts at $t_{3}$ when $S_{2}$ is turned off. $i_{L r 2}$ charges $C_{2}$ to $V_{\text {in }} / 2$ and discharges $C_{3}$ to zero. The $L L C$ converter is operated at $f_{s w}$ (switching frequency) $\approx f_{r}$ (series resonant frequency). Thus, the inductor current $i_{L r 2}$ is lagging with respect to the input fundamental voltage $v_{a c, f}$.

Mode 5 [ $\left.\boldsymbol{t}_{4}-\boldsymbol{t}_{5}\right]$ : Mode 5 starts at $t_{4}$ when the capacitor $C_{3}$ is discharged to zero. Since $i_{L r 1}\left(t_{4}\right)+i_{L r 2}\left(t_{4}\right)>0$, the anti-parallel diode of $S_{3}$ is conducting. $S_{3}$ can be turned on under ZVS due to the help of the $L L C$ converter. In this mode, $D_{a}, D_{r 2}$ and $D_{r 4}$ are on, $v_{a b}=-V_{i n} / 2, v_{a c}=0$, and $v_{r}=v_{C c}$. The output inductor voltage $v_{L o}=v_{C c}-V_{o 1}<0$ and $i_{L o}$ decreases. The primary inductor voltage $v_{L r 1}=n_{1} v_{C C}-V_{i n} / 2<0$ so that $i_{L r 1}$ decreases with a slope of $\left(n_{1} v_{C c}-V_{i n} / 2\right) / L_{r 1}$ until $i_{a}=i_{L o}$. In the $L L C$ converter, $C_{r}$ and $L_{r 2}$ are resonant with the input voltage $v_{a c}=0$, and $i_{L r 2}$ decreases in this mode. During this time interval, $i_{a}$ increases from zero to $i_{L o}$, and $i_{C c}$ increases from $-i_{L o}$ to zero. The time interval in this mode is given as:

$$
\Delta t_{45}=t_{5}-t_{4} \approx \frac{L_{r 1} I_{L o}}{n_{1} V_{\text {in }} / 2-n_{1}^{2} v_{C c}}
$$

In this mode, the three-level converter and the $L L C$ converter transfer energy from the input to the output load. The ac terminal voltage $v_{a b}=-V_{i n} / 2$ and diode $D_{a}$ conducts to obtain the rectified voltages $v_{r}=v_{C c}$. The duty loss in mode 5 is given as: 


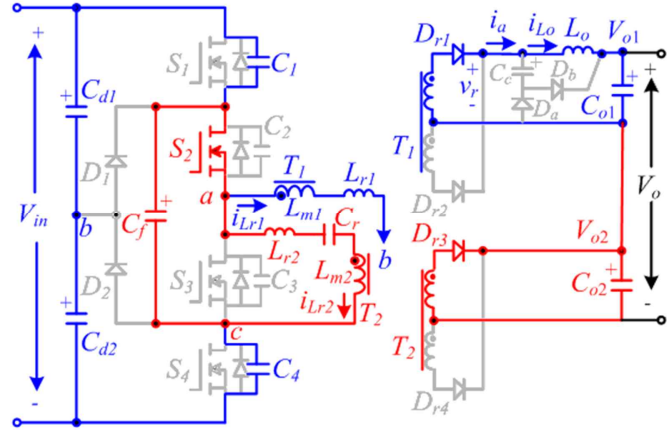

(a)

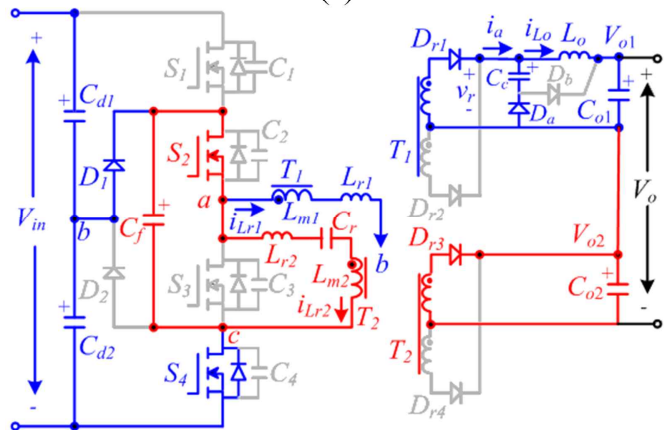

(b)

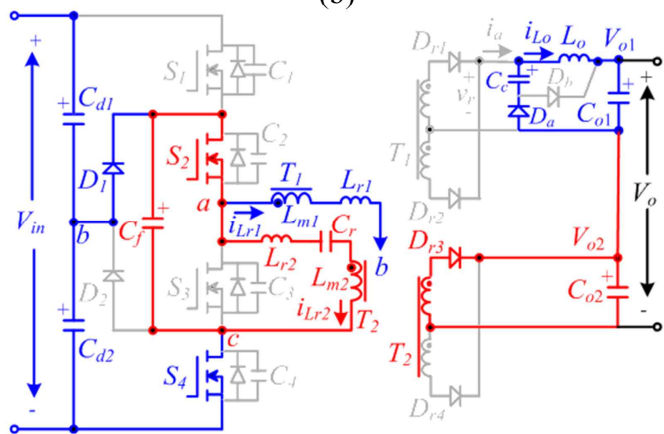

(c)

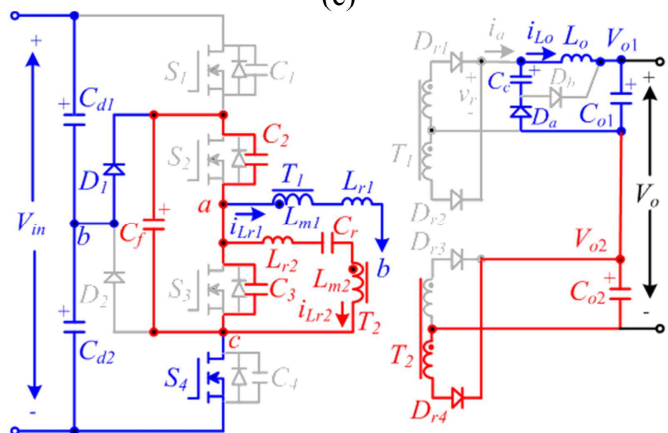

(d)

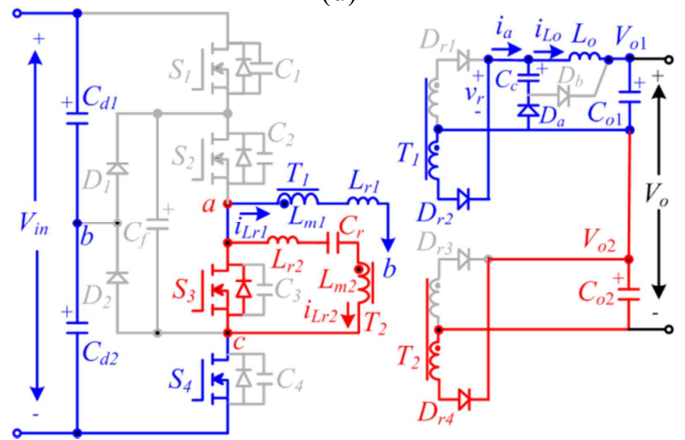

(e)

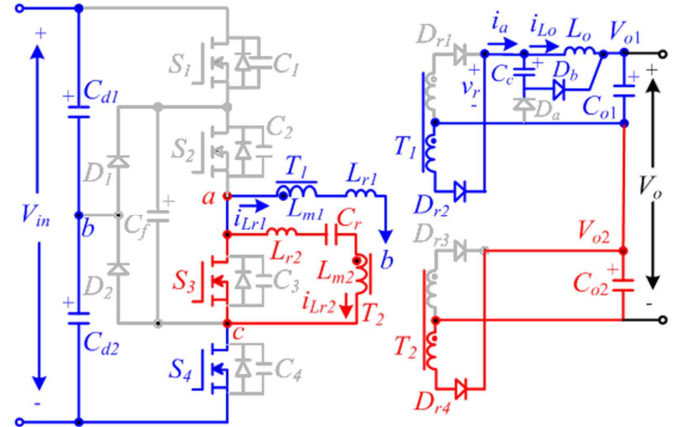

(f)

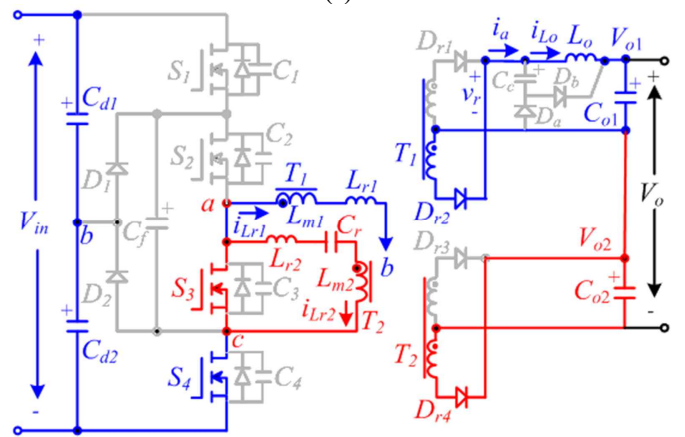

(g)

Fig. 4. Operation modes of the proposed converter in a half switching cycle. (a) Mode 1. (b) Mode 2. (c) Mode 3. (d) Mode 4. (e) Mode 5. (f) Mode 6. (g) Mode 7.

$$
\delta_{5}=\Delta t_{45} / T_{s} \approx \frac{L_{r 1} I_{L o} f_{s w}}{n_{1} V_{i n} / 2-n_{1}^{2} v_{C c}}
$$

Mode 6 [ $\left.\boldsymbol{t}_{5}-\boldsymbol{t}_{6}\right]$ : Mode 6 starts at $t_{5}$ when $i_{a}=i_{L o}$ and $i_{C c}=0$. Diode $D_{a}$ is off. The reflected primary inductance $L_{r 1} /\left(n_{1}\right)^{2}$ and $C_{c}$ are resonant with the resonant frequency $f_{R}=n_{1} /\left(2 \pi \sqrt{L_{r 1} C_{c}}\right)$. Thus, the diode $D_{b}$ is conducting in this mode. The output inductor current $i_{L o}$ increases with a slope of $v_{C C} / L_{o}$. The half of a resonant period, $1 /\left(2 f_{R}\right)$, is designed to be less than the minimum effective duty cycle time $\left(\delta_{\text {eff,min }} T_{s w} / 2\right)$. Then, the capacitor current $i_{C c}$ will be decreased to zero before $S_{4}$ is turned off. The rectified voltage $v_{r}=v_{C c}+V_{o 1}$, and the primary inductor current $i_{L r 1}=-\left(i_{L o}+i_{C c}\right) / n_{1}$. In this mode, energy is transferred from the input voltage to the output load through both the three-level converter and the $L L C$ circuit.

Mode 7 [ $\left.\boldsymbol{t}_{\boldsymbol{6}}-\boldsymbol{t}_{7}\right]$ : Mode 7 starts at $t_{6}$ when $i_{C c}=0$, and diode $D_{b}$ is off. The rectified voltage $v_{r} \approx V_{i n} /\left(2 n_{1}\right)>v_{C c}$, and $D_{a}$ is reverse biased. The output inductor voltage $v_{L o}=V_{i n} /\left(2 n_{1}\right)-V_{o 1}>0$, and $i_{L o}$ increases in this mode. This mode ends at $t_{7}$ when $S_{4}$ is turned off. Then, the circuit operations of the proposed converter in the first half of a switching period are completed.

\section{CONVERTER PERFORMANCE ANALYSIS}

There are two circuits, a three-level PWM circuit and an $L L C$ circuit, in the proposed converter. The three-level converter transfers energy from the input voltage $V_{i n}$ to the 
output $V_{o 1}$ in modes 5-7 during the first half of the switching cycle. The $L L C$ converter transfers energy from the capacitor $C_{f}$ to the output $V_{o 2}$ within a full switching period. Since the $L L C$ converter is operated as an unregulated dc-dc converter with a switching frequency $f_{s w}$ that is close to the series resonant frequency $f_{r}$, the lagging-leg switches $S_{2}$ and $S_{3}$ are easily turned on at ZVS from zero to full load, and the circulating current of the $L L C$ converter is at its minimum due to $f_{s w} \approx f_{r}$. Based on the fundamental frequency analysis of the $L L C$ converter, the ac voltage gain of the $L L C$ converter at the switching frequency is equal to unity. Thus, the designed dc voltage gain of the $L L C$ circuit is equal to the ac voltage gain of the $L L C$ circuit at the series resonant frequency, i.e. $M_{d c, L L C}=4 n_{2} V_{o 2} / V_{\text {in }}=1$. The unregulated output voltage $V_{o 2}$ of the $L L C$ converter is obtained as:

$$
V_{o 2}=V_{\text {in }} /\left(4 n_{2}\right)
$$

The ZVS condition of the leading-leg switches $S_{1}$ and $S_{4}$ is achieved by the primary inductance $L_{r 1}$ and output inductance $L_{o}$ given in (1). The other ZVS condition of $S_{1}$ and $S_{4}$ is that the dead time between $S_{1}$ and $S_{4}$ must be greater than $\Delta t_{01}$ given in (2). The charge and discharge times of $S_{1}-S_{4}$ are much less than the time intervals in the other modes, and only modes 2, 3, 5, 6 and 7 are considered in the following analysis. In mode 6 , the average capacitor voltage $V_{C c}=V_{\text {in }} /\left(2 n_{1}\right)-V_{o 1}$. The flux balance condition on the output inductance $L_{o}$ is given as:

$$
\begin{aligned}
& \left(\delta-\delta_{5}-\delta_{6}\right)\left(V_{i n} /\left(2 n_{1}\right)-V_{o 1}\right)+\delta_{6} V_{C c} \\
& =\left(0.5-\delta+\delta_{5}\right)\left(V_{o}-V_{C c}\right)
\end{aligned}
$$

where $\delta_{6}$ is the duty cycle in mode 6. Substitute $V_{C c}=V_{\text {in }} /\left(2 n_{1}\right)-V_{o 1}$ into (7). Then, the output voltage $V_{o 1}$ of the three-level converter is obtained as:

$$
V_{o 1}=\frac{V_{\text {in }}}{4 n_{1}\left(1-\delta+\delta_{5}\right)}=\frac{V_{\text {in }}}{4 n_{1}\left(1-\delta_{\text {eff }}\right)}
$$

where the effective duty cycle $\delta_{\text {eff }}=\delta-\delta_{5}$, and $\delta$ is the duty ratio of the proposed converter when $\left(S_{1}\right.$ and $\left.S_{2}\right)$ or $\left(S_{3}\right.$ and $S_{4}$ ) are in the on-state. The output voltages of the three-level converter and the $L L C$ converter are connected in series so that the output voltage $V_{o}$ of the proposed converter is expressed as:

$$
V_{o}=V_{o 1}+V_{o 2}=\frac{V_{\text {in }}}{4 n_{1}\left(1-\delta_{\text {eff }}\right)}+\frac{V_{\text {in }}}{4 n_{2}}
$$

The dc voltage conversion ratio of the proposed converter is obtained as:

$$
M_{d c}=V_{o} / V_{\text {in }}=\frac{n_{2}+\left(1-\delta_{\text {eff }}\right) n_{1}}{4 n_{1} n_{2}\left(1-\delta_{\text {eff }}\right)}
$$

The ripple current of the output inductor $L_{o}$ is approximated as:

$$
\begin{aligned}
\Delta i_{L o} & =\left(V_{o 1}-V_{C c}\right)\left(0.5-\delta_{e f f}\right) T_{s w} / L_{o} \\
& \approx\left(2 V_{o 1}-\frac{V_{\text {in }}}{2 n_{1}}\right)\left(0.5-\delta_{e f f}\right) T_{s w} / L_{o}
\end{aligned}
$$

$$
L_{o} \geq\left(2 V_{o 1}-\frac{V_{\text {in }}}{2 n_{1}}\right)\left(0.5-\delta_{\text {eff }}\right) T_{s w} / \Delta i_{L o}
$$

The ripple currents, the maximum currents and the minimum currents of the magnetizing inductances $L_{m 1}$ and $L_{m 2}$ are obtained as:

$$
\begin{aligned}
& \Delta i_{L m 1} \approx V_{i n} \delta_{e f f} T_{s w} /\left(2 L_{m 1}\right), \quad \Delta i_{L m 2} \approx V_{i n} T_{s w} /\left(8 L_{m 2}\right) \\
& i_{L m 1, \max } V_{i n} \delta_{e f f} T_{s w} /\left(4 L_{m 1}\right), i_{L m 1, \min }=-V_{i n} \delta_{e f f} T_{s w} /\left(4 L_{m 1}\right) \\
& i_{L m 2, \max }=V_{i n} T_{s w} /\left(16 L_{m 3}\right), i_{L m 2, \min }=-V_{i n} T_{s w} /\left(16 L_{m 3}\right)
\end{aligned}
$$

The average diode currents of $D_{1}-D_{4} D_{b}$ are shown in (16) and (17).

$$
\begin{gathered}
i_{D 1, \mathrm{av}}=i_{D 2, a v} \approx \delta I_{o} \\
i_{D 3, \mathrm{av}}=i_{D 4, a v} \approx(0.5-\delta) I_{o}
\end{gathered}
$$

The voltage stresses of $D_{1}-D_{4}, D_{a}$ and $D_{b}$ are given as:

$$
\begin{gathered}
v_{D 1, \text { stress }}=v_{D 2, \text { stress }} \approx V_{\text {in }} / n_{1} \\
v_{D 3 \text {,stress }}=v_{D 4, \text { stress }} \approx 2 V_{o 2}=V_{\text {in }} /\left(2 n_{2}\right) \\
v_{D a \text {,stress }}=v_{D b \text {,stress }} \approx V_{o 1}=\frac{V_{\text {in }}}{4 n_{1}\left(1-\delta_{\text {eff }}\right)}
\end{gathered}
$$

\section{EXPERIMENTAL RESULTS}

First, the design procedure of the proposed converter is shown in this section to derive the main circuit components in a laboratory prototype. The electric specifications of the prototype circuit are $V_{\text {in }}=750 \mathrm{~V}-800 \mathrm{~V}, V_{o}=48 \mathrm{~V}$ and $I_{o, \text { rated }}=30 \mathrm{~A}$. The switching frequency $f_{s w}=100 \mathrm{kHz}$. The output voltage of the $L L C$ converter is assumed as $20 \mathrm{~V}$. The selected series resonant frequency of the $L L C$ converter is equal to the switching frequency $f_{s w}$. The DC gain of the $L L C$ converter at $f_{r}$ is equal to unity. Based on (6), the turns ratio of $T_{2}$ is obtained in (21).

$$
n_{2}=V_{i n, \max } /\left(4 V_{o 2}\right)=800 /(4 \times 20)=10
$$

The primary inductance, primary winding turns and secondary winding turns of $T_{2}$ are $480 \mu \mathrm{H}, 30$ turns and 3 turns, respectively. In the $L L C$ converter, the series resonant inductance $L_{r 2}=80 \mu \mathrm{H}$ and the series resonant capacitance $C_{r}$ $=32 \mathrm{nF}$. The series resonant frequency of the $L L C$ converter is close to $100 \mathrm{kHz}$. The maximum effective duty cycle $\delta_{\text {eff }}$ is assumed to be 0.4 . From (9), the turns ratio of $T_{1}$ is derived in (22).

$$
n_{1}=\frac{V_{i n, \min }}{4\left(1-\delta_{e f f}\right)\left(V_{o}-\frac{V_{i n, \min }}{4 n_{2}}\right)}=10.68
$$

The magnetizing inductance, primary winding turns and secondary winding turns of $T_{1}$ are $1.3 \mathrm{mH}, 64$ turns and 6 turns, respectively. The assumed duty cycle loss in mode 5 is 0.01 . The necessary primary inductance $L_{r 1}$ can be obtained from (5) and is given in (23).

$$
L_{r 1}=\frac{\delta_{5}\left(n_{1} V_{i n, \min } / 2-n_{1}^{2} v_{C c}\right)}{I_{L o, \text { rated }} f_{s w}} \approx 10.6 \mu \mathrm{H}
$$

From (11), the output inductance $L_{o}$ is obtained in (12). 


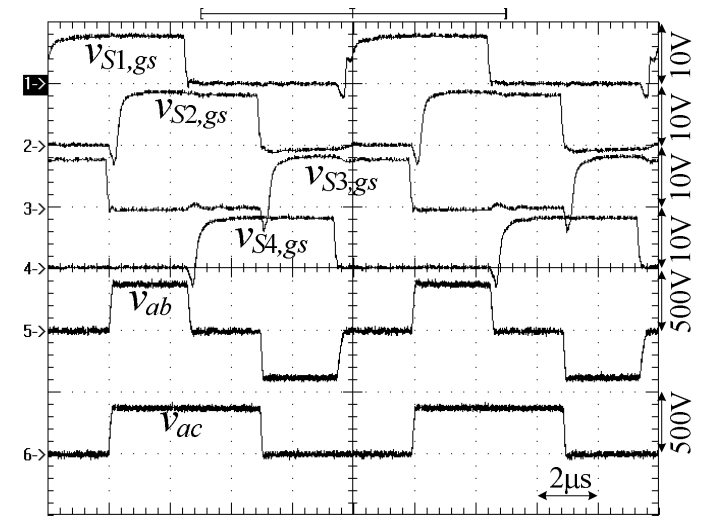

(a)

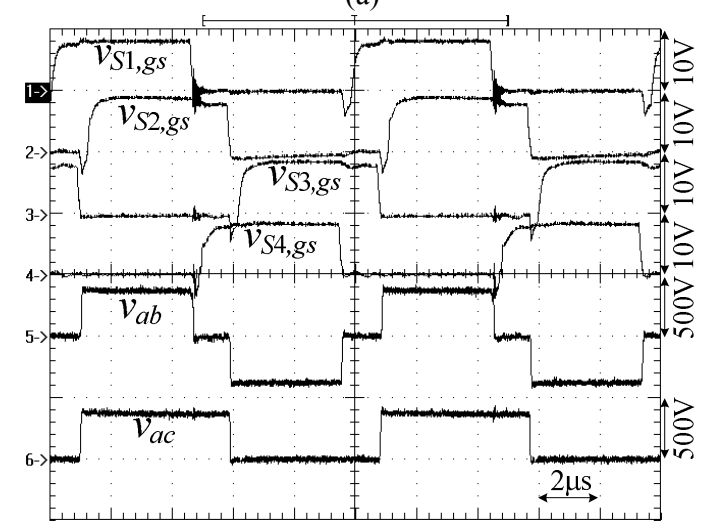

(b)

Fig. 5. Measured PWM signals of $S_{1}-S_{4}$ and ac side voltages $v_{a b}$ and $v_{a c}$ at (a) $25 \%$ load. (b) $100 \%$ load.



(a)

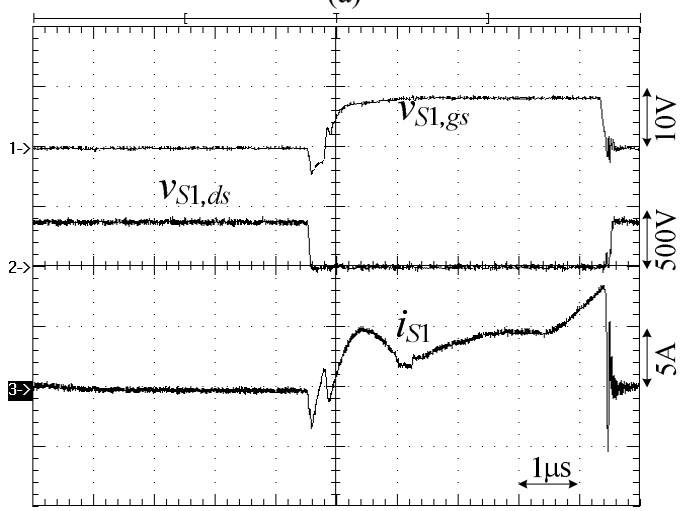

(b)

Fig. 6. Measured voltage and current of $S_{1}$ (leading-leg switch) at (a) $15 \%$ load (b) $100 \%$ load.

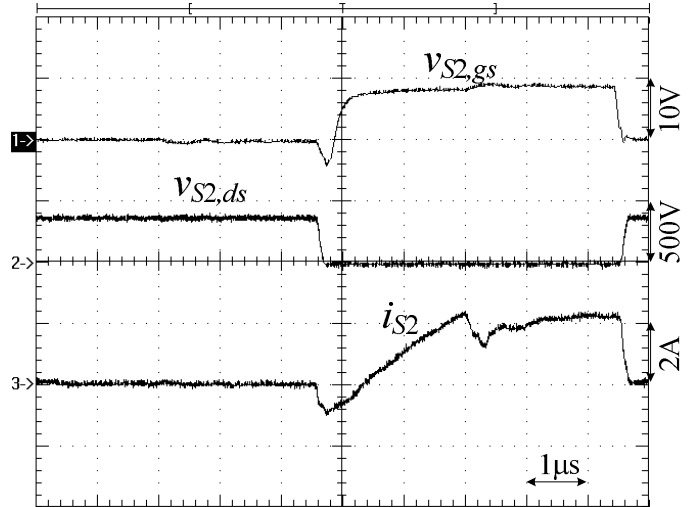

(a)

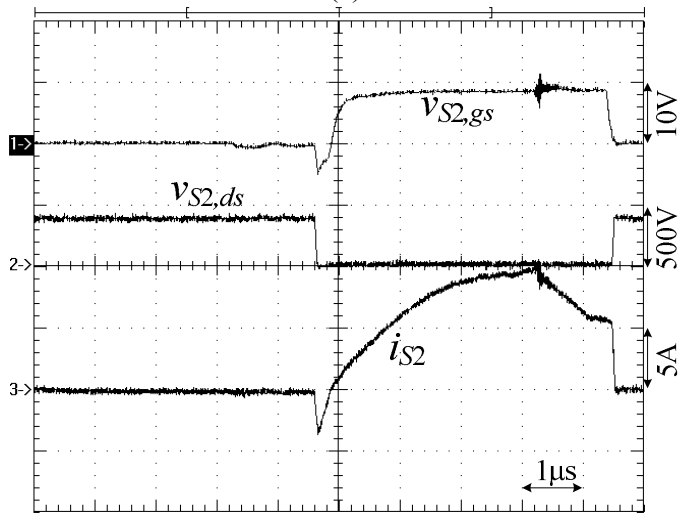

(b)

Fig. 7. Measured voltage and current of $S_{2}$ (lagging-leg switch) at (a) $15 \%$ load (b) $100 \%$ load.

The selected primary inductance $L_{r 1}$ is $10 \mu \mathrm{H}$ in the prototype circuit. From (12), the output inductance $L_{o}$ is obtained in (24) with $\Delta i_{L o} / I_{o, \text { rated }}=0.2$.

$$
L_{o} \geq\left(2 V_{o 1}-\frac{V_{i n, \min }}{2 n_{1}}\right)\left(0.5-\delta_{e f f}\right) T_{s w} / \Delta i_{L o}=3.5 \mu H
$$

In the prototype circuit, the adopted output inductance $L_{o}$ is $5 \mu \mathrm{H}$. Power MOSFETs (IRFP460) with $V_{D S}=500 \mathrm{~V}$ and $I_{D, r m s}=20 \mathrm{~A}$ are used for the switches $S_{1}-S_{4}$. Fast recovery diodes (VF30200C) with $V_{R R M}=200 \mathrm{~V}$ and $I_{F}=30 \mathrm{~A}$ are used as the rectifier diodes $D_{1}-D_{6}, D_{a}$ and $D_{b}$. The selected clamped diodes $D_{1}$ and $D_{2}$ are MUR860. The selected input split capacitances are $C_{d 1}=C_{d 2}=360 \mu \mathrm{F} / 450 \mathrm{~V}$, the flying capacitance $C_{f}=1 \mu \mathrm{F}$ and the output capacitances are $C_{o 1}=C_{o 2}=2200 \mu \mathrm{F}$.

Experimental results based on a laboratory prototype with the above circuit parameters are presented to verify the circuit performance. Fig. 5 gives the measured PWM signals of $S_{1}-S_{4}$ and the ac side voltages $v_{a b}$ and $v_{a c}$ at $25 \%$ and $100 \%$ loads. It can be seen that there are three voltage levels on $v_{a b}$ and two voltage levels on $v_{a c}$. The measured voltage and current of $S_{1}$ (leading-leg switch) at $15 \%$ and $100 \%$ loads are illustrated in Fig. 6. Fig. 7 gives the measured voltage and current of $S_{2}$ (lagging-leg switch) at $15 \%$ and $100 \%$ loads. From Figs. 6 and $7, S_{1}$ and $S_{2}$ are all turned on at ZVS at a $15 \%$ load. $\left(S_{1}, S_{4}\right)$ and $\left(S_{2}, S_{3}\right)$ are in the leading-leg and lagging-leg, 


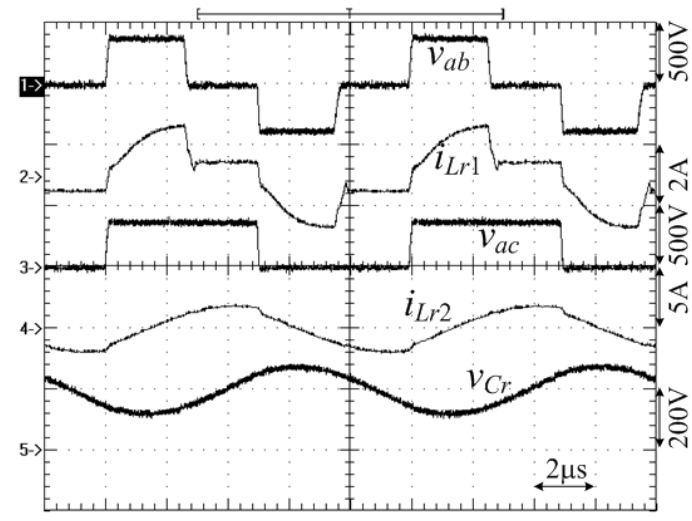

(a)

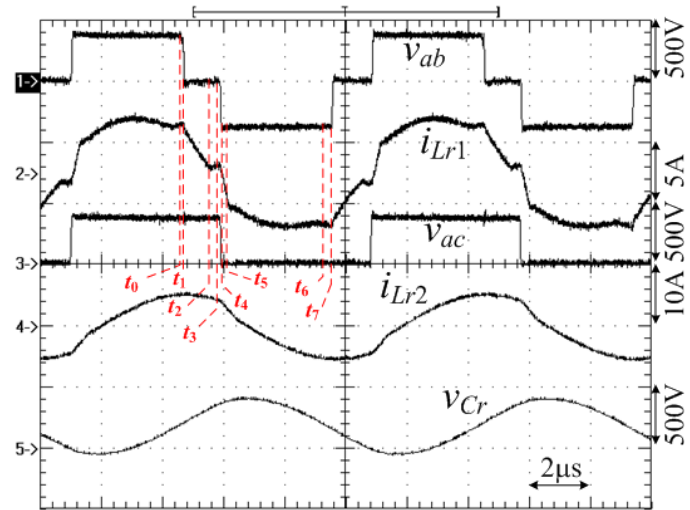

(b)

Fig. 8. Measured waveforms of ac side voltages $v_{a b}$ and $v_{a c}$, resonant capacitor voltage $v_{C r}$, and the primary currents $i_{L r 1}$ and $i_{\text {Lr2 }}$ at (a) $25 \%$ load (b) $100 \%$ load.

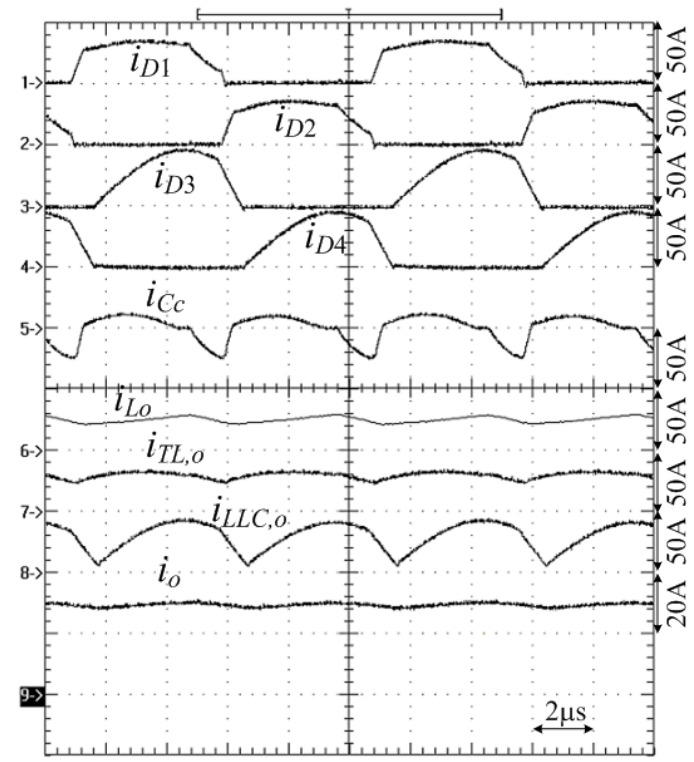

Fig. 9. Measured waveforms of diode currents $i_{D 1}-i_{D 4}$, clamped capacitor current $i_{C c}$, output inductor current $i_{L o}$, three-level converter output current $i_{T L, o}, L L C$ converter output current $i_{L L C, o}$ and load current $I_{o}$ at full load.

respectively. Thus, $S_{1}-S_{4}$ are all turned on at ZVS from $15 \%$ to full load conditions. Fig. 8 shows the test results of the ac side voltages $v_{a b}$ and $v_{a c}$, the resonant capacitor voltage $v_{C r}$, and the primary currents $i_{L r 1}$ and $i_{L r 2}$ at $25 \%$ and $100 \%$ loads.
There is no circulating current on $i_{L r 1}$ in the freewheeling interval $\left(v_{a b}=0\right)$, and the primary current $i_{L r 2}$ is a quasi-sinusoidal current. From the measured primary inductor current $i_{L r 1}$ in Fig. 8(b), it is clear than there are seven operation modes in the first half switching cycle and these measured waveforms verify the operation mode discussions in section III. Fig. 9 illustrates the experimental results of the diode currents $i_{D 1}-i_{D 4}$, clamped capacitor current $i_{C c}$, output inductor current $i_{L o}$, three-level converter output current $i_{T L, o}=i_{L o}+i_{D b}, L L C$ converter output current $i_{L L C, o}$ and load current $I_{o}$ at full load. The measured circuit efficiencies of the proposed converter are $94.5 \%, 95.3 \%$ and $93.2 \%$ at a $25 \%$ load, a $50 \%$ load and a $100 \%$ load, respectively. The measured maximum efficiency is $95.9 \%$ at an $80 \%$ load.

\section{CONCLUSION}

A hybrid ZVS converter is presented in this paper to reduce the circulating current loss in the freewheeling interval and to extend the ZVS range of the lagging-leg switches. The proposed hybrid converter includes a conventional three-level converter and a $L L C$ converter with shared lagging-leg switches. The switching frequency of the $L L C$ converter is close to the series resonant frequency to reduce the circulating current at the primary side and to help the lagging-leg switches turn on at ZVS from light load to full load conditions. A passive snubber is used on the secondary side of the three-level converter to reduce the circulating current during the freewheeling interval due to the fact that a reflected rectifier voltage is applied to the leakage inductance. The outputs of the two converters are connected in series to transfer energy from the input to the output load within the whole switching cycle. When compared to the conventional three-level PWM converter, the proposed hybrid converter has less circulating current losses and a wider range of ZVS operation. Finally, the effectiveness and performance of the proposed converter are verified by experimental results with a $1.44 \mathrm{~kW}$ prototype circuit.

\section{ACKNOWLEDGMENT}

This project is supported by the National Science Council of Taiwan under Grant NSC 102-2221-E-224 -022 -MY3.

\section{REFERENCES}

[1] I.-H. Cho, K.-M. Cho, J.-W. Kim, and G.-W. Moon, “A new phase-shifted full-bridge converter with maximum duty operation for server power system," IEEE Trans. Power Electron., Vol. 26, No. 12, pp. 3491-3500, Dec. 2011.

[2] H. Kato, H. Matsuo, T. Ito, S. Kawazu, D. Kawahara, S. Motomura, and R. Hamaguchie, "Power efficiency improvement of the full ridge current resonant dc-dc converter," in Proc. of IEEE INTELEC Conf., pp. 1-5, 2011. 
[3] D. Gautam, F. Musavi, M. Edington, W. Eberle, and W. G. Dunford, "An automotive on-board 3.3kW battery charger for PHEV applications,” in Proc. of IEEE VPP Conf., pp. 1-6, 2011.

[4] T. Mishima, K. Akamatsu, and M. Nakaoka, "A high frequency-link secondary-side phase-shifted full-bridge soft-switching PWM DC-DC converter with ZCS active rectifier for EV battery chargerd," IEEE Trans. Power Electron., Vol. 28, No. 12, pp. 5758-5773, Dec. 2013.

[5] S.-K. Han, G.-W. Moon and M.-J. Youn, “A voltage-balanced phase-shifted three-level DC/DC converter operating from high-input voltage," IEEE Power Electron. Letters, Vol. 1, No. 3, pp. 74-77, Sep. 2003.

[6] F. Canales, P. Barbosa, and F. C. Lee, "A zero-voltage and zero-current switching three-level DC/DC converter," IEEE Trans. Power Electron., Vol. 17, No. 6, pp. 898-904, Nov. 2002.

[7] J. P. Rodrigues, S. A. Mussa, I. Barbi, and A. J. Perin, "Three-level zero-voltage switching pulse-width modulation DC-DC boost converter with active clamping," IET Proc. Power Electron., Vol. 3, No. 3, pp. 345-354, 2010.

[8] J. A. Sabate, V. Vlatkovic, R. B. Ridlry, F. C. Lee, and B. H. Cho, "Design considerations for high-voltage high-power full-bridge zero-voltage-switched PWM converter," in Proc. of IEEE-APEC Conf., pp. 275-284, 1990.

[9] Y. Jang, M. M. Jovanovic, and Y. M. Chang, "A new ZVS-PWM full-bridge converter," IEEE Trans. Power Electron., Vol. 18, No. 5, pp. 1122-1129, Sep. 2003.

[10] X. Wu, J. Zhang, X. Xie, and Z. Qian, “Analysis and optimal design considerations for an improved full-bridge ZVS dc-dc converter with high efficiency," IEEE Trans. Power Electron., Vol. 21, No. 5, pp.1225-1233, Sep. 2006.

[11] W. Yu, J. S. Lai, W.-H. Lai, an H. Wan, "Hybrid resonant and PWM converter with high efficiency and full soft-switching range,” IEEE Trans. Power Electron., Vol. 27, No. 12, pp. 4925-4233, Dec. 2012.

[12] Y. Chen and Y. Kang, “An improved full-bridge dual-output dc-dc converter based on the extended complementary pulse width modulation concept," IEEE Trans. Power Electron., Vol. 26, No. 11, pp. 3215-3229, Nov. 2011.

[13] L. H. Mweene, C. A. Wright, and M. F. Schlecht, “A $1 \mathrm{kw}$ $500 \mathrm{kHz}$ front-end converter for a distributed power supply system,” IEEE Trans. Power Electron., Vol. 6, No. 3, pp. 398-407, Jul. 1991.

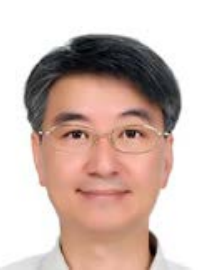

Bor-Ren Lin received his B.S. degree in Electronic Engineering from the National Taiwan University of Science and Technology, Taipei, Taiwan, in 1988, and his M.S. and Ph.D. degrees in Electrical Engineering from the University of Missouri, Columbia, MO, USA, in 1990 and 1993, respectively. From 1991 to 1993, he was a Research Assistant with the Power Electronic Research Center, University of Missouri. Since 1993, he has been with the Department of Electrical Engineering, National Yunlin University of Science and Technology, Douliou, Taiwan, where he is currently a Distinguished Professor. He is an Associate Editor of the Institution of Engineering and Technology Proceedings-Power Electronics and the Journal of Power Electronics. His current research interests include power-factor correction, multilevel converters, active power filters, and soft-switching converters. He has authored more than 200 published technical journal papers in the area of power electronics. Dr. Lin is an Associate Editor of the IEEE Transactions on Industrial Electronics. He was a recipient of Research Excellence Awards, in 2004, 2005, 2007 and 2011 from the College of Engineering and the National Yunlin University of Science and Technology. He received Best Paper Awards from the 2007 and 2011 IEEE Conference on Industrial Electronics and Applications, the 2007 Taiwan Power Electronics Conference, the 2009 IEEE-Power Electronics and Drive Systems Conference, the 2012 Taiwan Electric Power Engineering Conference, and the 2014 IEEE-International Conference on Industrial Technology.

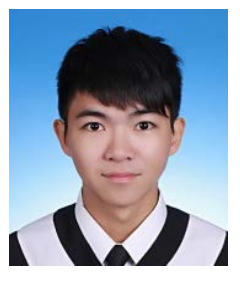

Jia-Sheng Chen is presently working toward his M.S. degree in Electrical Engineering at the National Yunlin University of Science and Technology, Yunlin, Taiwan (ROC). His current research interests include the design and analysis of power factor correction techniques, switching mode power supplies and soft switching converters. 